\title{
GAMBARAN PENGETAHUAN IBU RUMAH TANGGA TENTANG MENYIKAT GIGI TERHADAP def-t DAN DMF-T PADA SISWA-SISWI SD NEGERI 060930 TITI KUNING KECAMATAN MEDAN JOHOR TAHUN 2014
}

\author{
Aminah Br. Saragih ${ }^{1}$, Herlinawati ${ }^{2}$ \\ Jurusan Keperawatan Gigi Poltekkes Kemenkes Medan
}

\begin{abstract}
Abstrak
Menyikat gigi sangat penting untuk menjaga kesehatan gigi dan mulut. Tindakan membersihkan gigi dari plak dan sisa makanan yang biasanya menumpuk pada permukaan gigi maupun disela-sela gigi, dengan menggunakan alat sikat gigi dan dilakukan sehari-hari. Penelitian yang digunakan adalah penelitian diskriptif dengan metode survei yang bertujuan untuk mengetahui gambaran pengetahuan ibu rumah tangga tentang menyikat gigi terhadap def-t dan DMF-T pada Siswa/i SD Negeri 060930 Titi Kuning Kecamatan Medan JohorTahun 2014. Sampel penelitian adalah total populasi yaitu (40 orang). Kuesioner di isi langsung oleh ibu rumah tangga. Hasil penelitian tentang ibu yang memiliki pengetahuan dengan kriteria baik 35 orang $(87,5)$, kriteria sedang 5 orang $(12,5)$ dan tidak ada yang memiliki kriteria buruk dalam tingkat pengetahuan ibu. Status karies gigi (def-t) memiliki jumlah decay (d) 192 dari 40 siswa (4,8\%), extrakcition (e), filling (f) tidak ada ditemukan. Status karies gigi (DMF-T) memiliki jumlah jumlah Decay (D) 32 dari 40 siswa $(0,8)$, Missing (M) dan Filling (F) tidak ada ditemukan. Berdasarkan hasil penelitian dapat disimpulkan bahwa ibu yang memiliki pengetahuan baik adalah 35 orang $(87,5 \%)$, decay (d) 192 dari 40 siswa $(4,8)$ dan Decay (D) 32 dari 40 siswa $(0,8)$. kepada ibu siswa agar lebih baik mengawasi dan memperhatikan anak saat menyikat gigi dan hendaknya ibu memilih sikat gigi yang dan tepat.
\end{abstract}

Kata kunci: Pengetahuan ibu rumah tangga, def-t, DMF-T

\section{PENDAHULUAN}

Menurut Undang-undang Kesehatan No. 36 Tahun 2009 Pasal 93 ayat 1 dan 2 yaitu pelayanan Kesehatan Gigi dan Mulut dilakukan untuk memelihara dan meningkatkan derajat kesehatan masyarakat yang dapat dilakukan dengan tindakan pencegahan penyakit gigi yang dilaksanakan oleh pemerintah setempat dan dapat juga dilakukan melalui pelayanan kesehatan gigi perseorangan, sekolah dan masyarakat.

Pembangun kesehatan bertujuan meningkakan kesadaran kemauan, serta kemampuan hidup sehat bagi setiap orang agar berwujud derajat kesehatan yang optimal. Oleh karena itu perlu perwujudan paradigma sehat yang mengutamakan pencegahan (preventive), meningkatkan kesehatan (promotif) serta upaya peningkatan (kurative) dan pemulihan kesehatan (rehabilitative).

Tubuh yang sehat tidak lepas dari keadaan rongga mulut yang sehat, kesehatan rongga mulut merupakan bagian integral dari kesehatan manusia setuhnya juga dalam meningkatkan kualitas dan produktivitas sumber daya manusia. Walaupun demikian banyak juga yang tidak tahu bahwa rongga mulut yang berperan penting dalam kesehatan tubuh.
Hasil Survey Kesehatan Rumah Tangga (SKRT) 2001 menyebutkan penyakit gigi dan mulut merupakan penyakit tertinggi keenam yang dialami masyarakat. Data tersebut juga menyebutkan bahwa sebanyak $61,5 \%$ masyarakat tidak menyikat gigi sesuai dengan anjuran dan 16,6\% bahkan tidak pernah menyikat giginya sama sekali.

Data hasil Survei Kesehatan Rumah Tangga (SKRT) 2004 yang dilakukan Departemen Kesehatan menyebutkan prevalensi karies (berlubang) gigi di Indonesia adalah 90,05\%. Sedangkan prevalensi penyakit periodontal $96,58 \%$.

Menurut Notoatmojo (2007), pengetahuan orang tua sangat penting untuk mendasari terbentuknya perilaku yang mendukung kebersihan gigi dan mulut anak. Pengetahuan melakukan pengindraan terhadap suatu objek tertentu untuk terbentuknya suatu tindakan. Pengetahuan juga dapat diperoleh secara alami maupun secara terencana yaitu melalui proses pendidikan. Peran orang tua, khususnya ibu sangat diperlukan didalam bimbingan, memberikan pengertian, menyediakan fasilitas kesehatan gigi dalam keluarga agar dapat memelihara kebersihan gigi dan mulut serta menghindari terbentuknya lubang gigi serta menyikat gigi. 
Indikator karies gigi dapat berupa prevalensi karies gigi dan dapat skor dari indeks karies. Indeks karies gigi yaitu angka yang menunjukkan jumlah gigi karies seseorang atau sekelompok orang. Indeks karies gigi sulung disebut def-t (d=decayed=gigi yang karies, $\mathrm{e}=$ extracted=gigi yang telah tercabut dan harus dicabut, $\mathrm{f}=$ filled=gigi yang sudah ditambal), def-t pertama kali diperkenalkan oleh Gruebbel pada tahun 1944 (James dan Beal, 1981). Indeks karies gigi (def-t) adalah jumlah karies gigi yang masih ditambal (d, untuk gigi sulung), ditambah dengan gigi karies yang tidak dapat di tambal lagi atau gigi dicabut (e, untuk gigi sulung) dan jumlah gigi karies yang sudah ditambal (f,untuk gigi sulung).

Indeks DMF-T diperkenalkan oleh klein $\mathrm{H}$, Palmer CE, Knutson JW pada tahun 1938 untuk mengukur pengalaman seseorang terhadap karies gigi. Pemeriksaannya meliputi pemeriksaan pada gigi (DMF-T). Semua gigi diperiksa kecuali gigi molar tiga karena gigi molar tiga biasanya tidak tumbuh, sudah dicabut atau kurang berfungsi. Indeks ini tidak menggunakan skor; pada kolom yang tersedia langsung diisi kode D (gigi yang karies), M (gigi yang hilang) dan F (gigi yang di tumpat) dan kemudian dijumlahkan sesuai kode. Rerata DMF-T adalah jumlah seluruh nilai DMF dibagi atas jumlah orang diperiksa.

Berdasarkan alasan di atas maka penulis tertarik melakukan penelitian di SD Negeri 060930 titi kuning Kec. Medan johor 2014 untuk mengetahui gambaran pengetahuan ibu rumah tangga tentang menyikat gigi terhadap def-t dan DMF-T pada siswa/i SD Negeri 060930 Titi Kuning Kecamatan Medan Johor.

\section{Tujuan Penelitian}

Penelitian ini bertujuan untuk mengetahui gambaran pengetahuan ibu rumah tangga tentang menyikat gigi terhadap def-t dan DMF-T pada siswa/i SD Negeri 060930 Titi Kuning Kecamatan Medan Johor 2014.

\section{Manfaat Penelitian}

Untuk menambah wawasan, pengetahuan dan pengalaman bagi penulis.

1. Menambah wawasan dan pengetahuan ibu tentang menyikat gigi pada anak.

2. Hasil penelitian diharapkan dapat menjadi bahan masukan dan sumber pengetahuan bagi peneliti selanjutnya.

\section{METODE PENELITIAN}

\section{Jenis dan Desain Penelitian}

Jenis penelitian yang digunakan adalah penelitian deskriftif, yang bertujuan untuk mengetahui gambaran pengetahuan ibu rumah tangga tentang menyikat gigi terhadap def-t dan DMF-T pada siswa/i SD Negeri 060930 Titi Kuning Kecamatan Medan Johor Tahun 2014.

\section{Populasi dan Sampel Penelitian}

Populasi adalah keseluruhan subjek peneliti. Apabila seseorang ingin meneliti semua elemen yang ada dalam wilayah peneliti, maka penelitinya adalah penelitian populasi (arikunto, 2002). Populasi dalam penelitian adalah ibu-ibu yang memiliki anak bersekolah di SD Negeri 060930 Titi Kuning Kecamatan Medan Johor dengan jumlah populasi adalah 421 orang.

Sampel merupakan objek yang diteliti dan dianggap mewakili seluruh populasi, (Notoatmojo). Aplikasi subjeknya kurang dari 100, lebih baik diambil semua sehingga menelitinya merupakan penelitian populasi. Tetapi, jika jumlah subjeknya besar, penelitian dapat diambil antara $10-15 \%$ atau $20-25 \%$ atau lebih. Peneliti mengambil sampel $10 \%$ dari $100 \%$ populasi. Sampel pada penelitian ini berjumlah 40 orang.

\section{Waktu Penelitian}

Penelitian ini dilaksanakan pada bulan Juli s/d Desember 2014

\section{HASIL DAN PEMBAHASAN}

\section{Hasil Penelitian}

Hasil penelitian tentang gambaran pengetahuan ibu rumah tangga tentang menyikat gigi terhadap def-t dan DMF-T pada siswa/i SD Negeri 060930 Titi Kuning Kecamatan Medan Johor Tahun 2014, diperoleh sebagai berikut:

Tabel 1. Distribusi Frekuensi DMF-T pada siswa/i SD Negeri 060930 Titi Kuning Kecamatan Medan Johor 2014

\begin{tabular}{lcc}
\hline & \multicolumn{2}{c}{ Pengetahuan } \\
\cline { 2 - 3 } Kriteria & $\begin{array}{c}\text { Sampel } \\
(\mathrm{n})\end{array}$ & $\begin{array}{c}\text { persentase } \\
(\%)\end{array}$ \\
\hline Baik & 35 & 87,5 \\
\hline Sedang & 5 & 12,5 \\
\hline Kurang & - & - \\
\hline Jumlah & 40 & 100 \\
\hline
\end{tabular}

Dari tabel 2 di atas, terlihat bahwa DMF-T pada siswa/i SD Negeri 060930 dengan jumlah Decay (D) 32 dari 40 siswa $(0,8)$, Missing dan Filling tidak ada ditemukan.

Tabel 2 Distribusi Frekuensi Gambaran Pengetahuan Ibu Rumah Tangga Tentang Menyikat Gigi. Status Karies Gigi

\begin{tabular}{lccc} 
def-t & Jumlah & $\begin{array}{l}\text { Sampel } \\
\text { (n) }\end{array}$ & Ratarata \\
\hline decay (d) & 192 & 40 & 4,8 \\
\hline extraction (e) & - & 40 & - \\
\hline filling (f) & - & - & 40 \\
\hline
\end{tabular}

Dari table 1 dapat dilihat bahwa ibu yang memiliki pengetahuan dengan kriteria baik ada 35 orang $(87,5 \%)$, kriteria sedang ada 5 orang $(12,5 \%)$ dan tidak ada 
yang memiliki kriteria buruk pada tingkat pengetahuan ibu rumah tangga.

Tabel 2. Distribusi Frekuensi def-t pada siswa/i SD Negeri 060930 Titi Kuning Kecamatan Medan Johor Tahun 2014

\begin{tabular}{lccc|}
\hline & \multicolumn{3}{c|}{ Status Karies Gigi } \\
\cline { 2 - 4 } DMF-T & $\begin{array}{c}\text { Jumlah Sampel } \\
(\mathrm{n})\end{array}$ & Rata-rata \\
\hline Decay (D) & 32 & 40 & 0,8 \\
\hline Missing (M) & - & 40 & - \\
\hline Filling (F) & - & 40 & - \\
\hline
\end{tabular}

Dari table 2 di atas, terlihat bahwa def-t pada Siswa/i SD Negeri 060930 dengan jumlah decay (d) 192 dari 40 siswa $(4,8)$, extraction (e) dan filling (f) tidak ada ditemukan.

\section{Pembahasan}

Dari table 1 dapat dilihat bahwa ibu yang memiliki pengetahuan dengan kriteria baik ada 35 orang (87,5\%), kriteria sedang ada 5 orang $(12,5)$ dan tidak ada yang memiliki kriteria buruk dalam tingkat pengetahuan ibu rumah tangga.

Berdasarkan data yang diperoleh dari jawaban kuesioner $40 \mathrm{ibu}$ rumah tangga (100\%) yang telah mengetahui pentingnya menyikat gigi, 34 ibu rumah tangga (85\%) sudah mengetahui tentang menyikat gigi dari media massa, karena banyak yang diiklankan atau dipromosikan tentang kesehatan gigi dan mulut di televisi. Menurut Ramadhan, AG (2010) berpendapat bahwa dalam menyikat gigi tidak perlu tekanan yang kuat karena sisa makanan masih memiliki kosistensi yang lunak sehingga mudah dibersihkan. 24 ibu rumah tangga (60\%) yang menjawab kuesioner dengan benar waktu menyikat gigi yang baik adalah 2-5 menit. Menurut Ramadhan AG (2010) bahwa menyikat gigi dua kali sehari pagi sesudah sarapan dan malam sebelum tidur, lama menyikat gigi dua sampai lima menit. Terdapat hanya 14 ibu ibu rumah tangga $(35 \%)$ yang menjawab benar tentang permukaan sikat gigi yang baik adalah bulu sikat gigi yang rata atau datar. Menurut Ramadhan,AG (2010) hal yang perlu diperhatikan dalam memilih sikat gigi yang baik yaitu:

1. Bulu sikat gigi yang lembut agar tidak melukai gusi dn mudah masuk ke sela-sela gigi.

2. Kepala sikat gigi yang berukuran kecil lebih bagus, karena bisa menjangkau seluruh bagian gigi dengan baik termasuk yang paling sulit dijangkau yaitu giigi yang paling belakang.

3. Model sikat gigi, sikat gigi yang baik adalah sikat gigi yang fit atau pas dengan mulut serta terasa nyaman saat digunakan.

4. Gagang sikat gigi, pilih sikat gigi yang tidak licin agar sikat gigi tetap bisa digunakan dengan baik walaupun dengan keadaan basah.

Terdapat 22 orang (55\%) yang mengetahui bahwa cara menyikat gigi geraham. Menurut Ginandjar. R (2012) cara menyikat gigi yang baik adalah menggosokan sikat gigi mulai dari belakang kanan atau kiri di gerakan kearah depan dan akhirnya pada gigi belakang kanan atau kiri dan untuk gigi geraham dataran pengunyahan (oklusal) dengan gerakan maju mundur.

Dari tabel 2 di atas, terlihat bahwa def-t pada siswa/i sd Negeri 060930 dengan jumlah decay (d) 192 dari 40 anak $(4,8)$ termasuk tinggi dalam prioritas masalah, menurut WHO prioritas yang baik adalah $\leq 2$.

Menurut Tarigan (2012) faktor yang mempengaruhi terjadinya karies gigi yaitu: Keturunan, Ras (suku), Jenis kelamin, Usia, Makanan, Vitamin, Unsur kimia, Air ludah, Plak.

Dalam penelitian ini extraction (e), filling (f) tidak ada di temukan.

Dari tabel 3 di atas, terlihat bahwa DMF-T pada siswa/i SD Negeri 060930 dengan jumlah Decay (D) 32 dari 40 siswa $(0,8)$ dalam prioritas masalah ini baik karena menurut WHO dalam prioritas masalah yang baik $\leq 2$.

Menurut Srigupta (2004) proses karies berkembang berdasarkan tiga tahap yaitu:

1. Berbagai bakteri yang ada dalam mulut membentuk asam, dari gula yang terkandung dalam makanan, yang melekat pada permukaan gigi.

2. Asam ini melarutkan email pelapis gigi berwarna putih yang menghancurkan susunan gigi. Proses ini dikenal dengan karies gigi dan menyebabkan gigi berlubang.

3. Lebih jauh lagi asam tersebut menyebabkan penetrasi karies dari Email ke gigi bagian dalam di bawah gigi kepala.

Missing (M) dan Filling (F) tidak ada ditemukan dalam penelitian ini.

\section{KESIMPULAN DAN SARAN}

\section{Kesimpulan}

Hasil penelitian gambaran pengetahuan ibu rumah tangga tentang menyikat gigi terhadap def-t dan DMF-T pada siswa/i SD Negeri 060930 Titi Kuning Kecamtan Medan Johor Tahun 2014 dapat disimpulkan sebagai berikut:

1. Tingkat Pengetahuan Ibu Tentang Menyikat Gigi.

- Baik berjumlah 35 orang $(87,5 \%)$

- Sedang berjumlah 5 orang $(12,5 \%)$ dan

- Tidak ada yang memiliki kategori Kurang

2. def-t pada Siswa/i SD Negeri 060930 Titi Kuning

- decay (d)=40 siswa $(4,8)$ memiliki decay berjumlah 192, dalam prioritas masalah ini buruk karena $\geq 2$. Sedangkan menurut WHO prioritas masalah yang baik $\leq 2$

- Dalam penelitian ini tidak ditemukan sampel extraction (e) dan filling

3. DMF-T pada Siswa/i SD Negeri 060930 Titi Kuning

- $\operatorname{Decay}(D)=40$ siswa/i $(0,8)$ memiliki Decay berjumlah 32 termasuk prioritas masalah yang baik karena $\leq 2$. 
- Dalam penelitian ini tidak ditemukan sampel Missing (M) dan Filling (F).

\section{A.5.2 Saran}

1. Kepada ibu siswa/i agar mengawasi dan memperhatikan anak saat menyikat gigi dan hendanya ibu memilih sikat gigi yang tepat.

2. Kepada pihak sekolah diharapkan untuk bekerja sama dengan PUSKESMAS setempat kesehatan gigi dan mulut melaksanakan program UKGS.

3. Pada siswa/i agar menyikat gigi secara rutin.

\section{DAFTAR PUSTAKA}

Edwana dan Joyston, S. 1991, dasar-dasar karies, EGC , Jakarta

Machfoedz, I. 2008, menjaga kesehatan gigi dan mulut anak-anak dan Ibu Hamil, fitramaya, Yogyakarta

Machfoedz, I. 2009,metodologi penelitian, fitramaya, Yogyakarta
Notoatmodjo, S. 2007, promosi kesehatan dan ilmu perilaku, rineka cipta, Jakarta.

Notoatmodjo, S.2010, metode penelitian kesehatan,

Rineka Cipta, Jakarta

Pantauli, S dan Hamada,T. 2008, menuju gigi dan mulut sehat pencegahan dan pemeliharan, KDT, Medan

Rahmadhan,AG. 2010, serba serbi kesehatan gigi dan mulut, bukune, Jakarta

Srigupta,AA. 2004, perawatan gigi dan mulut, EGC, Jakarta

Tarigan, S. 2012, karies gigi EGC, Jakarta

http://iimzizah.wordprees.com

http://yohandrie.blogspot.com./2012/04/gambaranpengetahua-murid--sd-kelas-ii.html

http://www.pps.unud.ac.id/thesis/pdf_thesis/unud-395758510795-bab\%20ii.docx20new\%20prop.pdf

http://basmarosandi.blogspot.com/1013/07/mekanismeterjadinya-lubang-gigi.html 